\title{
La conservación del templo de Debod. Problemas y propuestas para el futuro
}

\author{
Alfonso MARTÍN FLORES
}

La reconstrucción al aire libre del templo de Debod es la principal causa del deterioro sufrido por el monumento desde su salida de Egipto. Los trabajos realizados por el Ayuntamiento de Madrid, encargado de su conservación, han intentado paliar los daños y reducir la incidencia de los distintos factores de deterioro que operan sobre el edificio. Sin embargo, el control de dichos factores, directamente vinculados a su instalación, sólo podrá ser efectivo cuando ésta se modifique radicalmente, mediante su cubrición. Esta cubrición deberá tener en cuenta, además, los aspectos relacionados con el uso museístico del templo, incrementado notablemente en los últimos diez años. La construcción de un museo in situ puede ser la solución que contemple tanto su conservación como su explotación museística.

\section{The conservation of the temple of Debod. Problems and proposals for the future}

The open air reconstruction of the temple of Debod is the main reason for the deterioration suffered by the monument since its removal from Egypt. The work undertaken by the City Council of Madrid, the body responsible for its conservation, has been carried out with the intention of restricting further damage and reducing the effects of the various agents of deterioration that are affecting the building. Nevertheless, the control of these agents, directly linked to its location, will only be effective when the building is covered. Additionally, this covering must take into account issues relating to the increased use of the temple as a museum over the last ten years. The construction of a museum in situ could be the solution that would provide for the conservation of the building and its use as a museum.

KEY WORDs: Debod, deterioration agents, conservation, protecting covering, museum

$\mathrm{E}$ 1 templo de Debod es, sin lugar a dudas, uno de los más importantes exponentes de la cultura faraónica en nuestro país y el objeto más destacado que de esa civilización podemos contemplar en España. Su atractivo entre el público general es indiscutible: con cerca de 200.000 visitantes en 2008, fue uno de los museos madrileños más visitados. Sin duda, su localización al aire libre y su integración en el paisaje urbano madrileño, en un jardín histórico muy próximo al corazón de la ciudad, le proporcionan una gran accesibilidad que explica en buena medida sus altas tasas de visitantes. Pero esa misma circunstancia es también motivo constante de preocupación, no sólo para las instituciones y profesionales encargados de su gestión y conservación, sino para amplios sectores de opinión, tanto general como especializada, expresada en diferentes ocasiones y medios de todo tipo ${ }^{1}$. Una preocupación manifestada incluso antes de producirse la donación del templo a España y su traslado a Madrid. 
En el seno del Subcomité Consultivo de la República Árabe Unida para la Preservación de los Sitios y Monumentos de Nubia, organismo encargado de estudiar las solicitudes de los gobiernos para acoger alguno de los templos nubios destinados a su salida de Egipto en concepto de donación, hubo voces que señalaron que la intención española de reconstruir el templo de Debod al aire libre vulneraba las condiciones establecidas para la donación ${ }^{2}$. Ciertamente, su instalación al aire libre, en un parque madrileño, bajo unas condiciones climáticas diferentes a las del emplazamiento original, no era la mejor forma de asegurar la conservación del edificio, como así se ha demostrado.

Aunque no queda una constancia explícita, los negociadores españoles llegaron a un acuerdo con el estado egipcio en el que, si bien en un primer momento el templo sería reconstruido al aire libre, se comprometían, en un plazo medio y una vez resueltos los problemas técnicos que comportaba, a construir un edificio en cuyo interior se instalaría definitivamente el monumento. En este sentido caben interpretarse las alusiones a ese edificio contenidas en el acuerdo de donación entre el gobierno egipcio y el español, así como en los informes y comunicaciones de Martín Almagro Basch, colaborador técnico nombra- do por la Dirección General de Bellas Artes para las tareas de instalación y reconstrucción en Madrid, todos ellos fechados en 1970. Como es conocido, el edificio nunca fue construido, pero las consecuencias de una reconstrucción sin protección fueron ya evidentes en los meses siguientes a su inauguración en 1972.

La instalación del templo al aire libre no es, en rigor, la única causa del deterioro sufrido por el monumento. Procesos naturales y antrópicos desarrollados a lo largo de sus siglos de existencia han determinado la forma en que el templo ha llegado hasta nuestros días: su abandono y ruina, con la consiguiente pérdida de bloques, la prolongada inmersión bajo las aguas del embalse de la presa de Asuán, las acciones restauradoras, el desmontaje, traslado y reconstrucción del templo, y su condición de museo son otras tantas causas de su estado. Sin embargo, desde su llegada a Madrid es la instalación al aire libre la más importante y la que mayor influencia ejerce en el desarrollo de los factores degradantes que operan sobre el monumento. Factores, que directa o indirectamente están relacionados con esa instalación y que son difíciles de controlar o erradicar sin antes modificarla.

1. La comunidad egiptológica hispana ha mostrado en varias ocasiones su interés por el estado de conservación del Templo. Las más recientes en el II Congreso Ibérico de Egiptología en 2001 (Cervelló, Díaz de Cerio y Rull 2005:12) y en este mismo III Congreso en 2006.

[64] 2. Las condiciones para la donación de los templos fueron definidas en distintas reuniones de los órganos consultivos de la Campaña de Salvamento. Los criterios relativos a conservación se señalaron en la II sesión del Subcomité Consultivo de la República Árabe Unida para la Preservación de los Sitios y Monumentos de Nubia (Marzo de 1966): el monumento donado debería ser "expuesto en un lugar público o edificio, conforme a las condiciones requeridas para su mejor conservación y su mensaje cultural"; y en la III de ese mismo Subcomité (Marzo de 1967), la misma en que se adoptó recomendar al Comité Ejecutivo la donación del templo de Debod a España, en cuya recomendación se señalaba:

“a. (...) deberá ser expuesto en un lugar público donde pueda ser visto y estudiado por el mayor número posible de visitantes.

b. Bajo ninguna circunstancia deberá el monumento ser expuesto al aire libre, sino que deberá ser alojado en un edificio especialmente construido o reformado para ese propósito.

c. Para evitar la disgregación de los bloques de piedra, deberán ser objeto de un tratamiento químico in situ, antes de ser trasladado." 


\section{Factores de deterioro del TeMPlo de Debod ${ }^{3}$}

\section{Factores Ambientales}

\section{Humedad}

Es el factor más importante y perjudicial para la conservación del edificio desde su establecimiento en Madrid. El régimen de precipitaciones madrileño, con valores que oscilan entre los 400 y los 500 $\mathrm{mm}$ anuales, contrasta con la práctica ausencia de lluvias en la región nubia ( $10 \mathrm{~mm}$. anuales). El agua incide directamente en los paramentos mediante el hostigo, su precipitación desde la cubierta, la existencia de filtraciones y goteras o por capilaridad produciendo distintos tipos de erosión y pérdidas de volumen en los bloques. Pero el agua también se introduce en los sillares, circulando por el interior de las piedras, afectando a su estructura interna, abriendo grietas y arrastrando sales a la superficie que forman costras blanquecinas, eflorescencias, directamente responsables de pérdidas de material en los estratos superficiales. Es esta afectación de sales solubles la alteración de mayor importancia que hoy sufre el templo, y es especialmente grave en aquellas superficies parietales decoradas con relieves, como la capilla de Adijalamani o el vestíbulo.

La humedad favorece, por otra parte, la presencia de algas y líquenes en las zonas exteriores de umbría y es el vehículo idóneo para la penetración de contaminantes en los sillares.

\section{Contaminación atmosférica}

Junto con la humedad, la contaminación atmosférica es, en los grandes núcleos urbanos, otro de los elementos más perjudiciales para la conservación de monumentos, aumentando el grado y la velocidad de su deterioro.
En el caso de Debod, no constituye uno de los factores de deterioro más graves, si lo comparamos con otros edificios y monumentos madrileños situados en zonas más expuestas. Los niveles de contaminación en la estación de control más cercana, en Plaza de España, suelen ser los más bajos en el conjunto de las estaciones medioambientales madrileñas. La localización del templo, retirado de vías de tráfico rodado, en un paraje bien ventilado y dentro de una zona arbolada, aminoran su incidencia.

Más peligrosa es, sin embargo, la acción combinada de la contaminación atmosférica y de la humedad. Los contaminantes disueltos en el agua de lluvia incrementan su acidez y, una vez en el interior de los bloques, producen cambios en la estructura química de las piedras, provocando la disolución de los carbonatos cementantes de la arenisca y la formación de sulfatos, responsables de la formación de costras y la descohesión de la piedra.

\section{Factores estructurales}

Junto a los factores ambientales, hay que destacar los estructurales, derivados de los materiales constructivos del edificio y sus distintos estados de conservación y del funcionamiento estructural de la fábrica y la estabilidad del subsuelo en el que se asienta que provocan grietas, fisuras e, incluso, la rotura de sillares.

Los bloques originales, de arenisca, mostraban a su llegada a Madrid un estado general bastante degradado, con un escaso grado de cimentación, abundantes y graves exfoliaciones y numerosas roturas. Así mismo, eran visibles estriados, vermiculaciones y alveolizaciones, alteraciones debidas al largo periodo de inmersión del templo bajo las aguas de la primera Presa de Asuán. 
Algunos sillares presentaban erosiones, roturas o pérdidas ocasionadas en las tareas de desmontaje del templo en Nubia y prácticamente todos exhibían numerosos recrecidos de cemento y mortero debidos a la restauración de Alexander Barsanti en 1911, a los que se añadirían otros aplicados ya en Madrid. A estos recrecidos se suma un número indeterminado de elementos de hierro (llaves, vástagos y grapas) utilizados en esa misma restauración. La situación del templo al aire libre ha agravado estos problemas y ha provocado otros nuevos, como la generalizada precipitación de sales solubles en las superficies de los muros, procedentes de los propios bloques y de los añadidos de cemento, o la rotura de sillares debida a la corrosión deformante expansiva sufrida por los elementos metálicos indicados. En ambas alteraciones la humedad sería el factor desencadenante.

Por su parte, los sillares de Villamayor, más blandos y porosos que los originales y de peor calidad, han desarrollado una amplia gama de patologías. En algunas zonas, muestran un estado de conservación muy grave, con grandes pérdidas de material pétreo, principalmente en las fachadas este, norte y oeste, en las que la incidencia de la humedad agrava su estado.

\section{Factores biológicos}

La instalación al aire libre supone, además, la presencia de algunas especies animales que utili[66 ] zan el templo como lugar de nidificación, apoyo, abrigo, o cazadero. En el caso de la avifauna urbana (palomas, gorriones y vencejos, principalmente), su presencia se traduce en manchas de excrementos, algunas de grandes dimensiones, sobre las superficies verticales de las fachadas y el interior de los pilonos, o en el aporte de restos orgánicos al interior de la estructura a través de los intersticios utilizados para nidificación. Si bien el daño estético es menos importante, el quí- mico es potencialmente más grave por el aporte de sales solubles y de ácidos que pueden provocar procesos de corrosión en el material pétreo. Además, los excrementos sirven de nutrientes a bacterias y hongos. Junto a los animales, los organismos vegetales son también factores de alteración importantes. Especialmente líquenes y musgos que alcanzan su mayor expansión en las fachadas norte y oeste, de mayor umbría y humedad. Su presencia aumenta la retención de agua sobre la piedra. La acidez que aportan algunos de estos tipos de flora produce alteraciones de orden químico en las superficies, con resultados de corrosión. Por su parte, los rizoides de los musgos penetran en la piedra fracturándola y disgregándola.

\section{Factores antrópicos}

Otro importante grupo de factores de riesgo son los derivados de la acción humana directa, entre ellos la visita pública y los actos de vandalismo.

Acceso público y conservación suelen ser dos elementos contradictorios, aunque, en el caso de un museo, obligatorios e insoslayables. La estructura compleja del templo y las pequeñas dimensiones de sus salas constituyen un riesgo añadido ante la visita masiva al edificio.

A diferencia de los otros templos donados por el estado egipcio e instalados en museos, cuyo interior no es visitable o lo es solo de forma parcial, en el templo de Debod se incrementó su accesibilidad, a fin de justificar el sacrificio de las otras condiciones relativas a su conservación. Desde 2001, la cifra de visitantes al templo ha crecido a un fuerte ritmo. Los análisis de visitantes y de ocupación de espacios nos han revelado la existencia de un problema de ocupación generalizado que llega a ser muy grave los sábados y los domingos, con una saturación del espacio muy por 
encima de la capacidad del edificio. El acceso masivo del público a su interior incide directamente en el deterioro de los sillares mediante erosiones de su superficie, bien sean realizadas de forma accidental, en especial en los accesos a las distintas estancias, bien intencionadas, llegando en ocasiones a producir daños de cierta importancia. La gran afluencia de visitantes incrementa, además, la temperatura y aporta humedad al interior del edificio.

Un capítulo aparte lo constituyen los episodios de vandalismo en forma de inscripciones, graffiti o pintadas. Se trata de actuaciones generalmente individuales y muy rápidas, limitadas a los elementos informativos exteriores, a los muros verticales del zócalo en el que se levanta el templo o al acceso a la planta sótano, por lo que su incidencia en la conservación es menor. No obstante, en dos casos los graffiti se han realizado sobre la fachada oeste del templo, cercanos a los relieves de la esquina suroeste. El progresivo deterioro, en los últimos años, de la seguridad en el parque y su inclusión entre las zonas de diversión nocturna de la ciudad, son nuevos elementos de preocupación, ya que pueden convertir el templo en posible objetivo de acciones vandálicas regulares.

Todos los factores reseñados actúan sobre el templo de forma conjunta y combinada, incrementado así su gravedad. Afectan a los distintos tipos de bloques y están presentes tanto en el exterior, como en el interior, si bien la humedad es cualitativamente más importante en las estancias interiores del templo y especialmente dañina en aquellas decoradas.

\section{Actuaciones Realizadas (1991-2008)}

Las principales actuaciones en materia de conservación abordadas en Debod han tenido una doble orientación: la adopción de medidas preventi- vas que minimicen la incidencia de los factores de riesgo enunciados, por un lado, y la restauración y reparación de los daños y deterioros según se producían o se iban haciendo evidentes con el transcurso del tiempo, por otro.

\section{La conservación preventiva}

Las tareas de conservación preventiva han estado dirigidas especialmente a evitar la entrada de agua y humedad al interior de las estructuras del templo que, como se ha afirmado, es el principal factor de su deterioro y a protegerlo de la acción antrópica.

Para impedir las filtraciones desde el piso superior se ha instalado una doble cubierta mediante la aplicación de planchas de plomo sobre una capa termoaislante de $10 \mathrm{~cm}$, directamente aplicada sobre la cubierta preexistente después de su revisión y sellado. Esta actuación ha sido completada posteriormente con la adecuación de los patios interiores de la terraza, sustituyendo su carpintería, canalones y bajantes y colocando una cubierta de planchas de zinc que asegure su estanqueidad. Además de evitar filtraciones, las actuaciones en la cubierta han pretendido aislar térmicamente la planta superior, algo no conseguido de forma satisfactoria.

En previsión de posibles deterioros por roturas en cañerías, se ha incorporado al mantenimiento regular la prospección endoscópica de la red vertical y horizontal de evacuación de aguas procedentes de las cubiertas, tanto del templo como de los pilonos. Estas prospecciones incluyen la acción directa sobre cualquier anomalía observada, antes de que pueda producirse un daño. En varias zonas del zócalo en el que se alza el templo se ha procedido a levantar las baldosas de granito y a restablecer las pendientes. De ese modo se intenta drenar el agua superficial procedente de la lluvia y evitar su acumulación, en forma de charcos, junto a la base de los paramentos. 
Así mismo se han reparado e impermeabilizado los estanques que flanquean el templo al este y al oeste y que tenían grandes pérdidas de agua que podían afectar a la cimentación del complejo. En este mismo sentido se ha procedido a localizar las conducciones de agua de servicio al parque en el recinto del templo y alrededores y sellarlas. Estas conducciones, que no estaban en uso, pero seguían operativas, rodeaban el edificio y penetraban en la zona de los pilonos, siendo, en caso de rotura, un peligro potencial para la conservación de esas estructuras.

La entrada masiva de aire húmedo y, en no pocas ocasiones, agua, al interior del templo a través de los grandes vanos de la fachada principal ha sido eliminada mediante la instalación de una mampara de vidrio con doble acristalamiento y cámara de aire, montada sobre una estructura metálica ligera anclada al suelo y techo, zonas donde no existen estructuras originales que pudieran resultar dañadas. La mampara tiene un nulo impacto visual desde el exterior, si bien provoca una importante distorsión del vestíbulo. En cualquier caso, se trata de una solución provisional hasta que se adopte otra constructiva más adecuada y es completamente removible sin que resulte dañada ninguna estructura original.

Por último se ha sustituido el sistema de climatización del templo, que ha sido ampliado hasta la terraza, y se ha revisado todo el circuito para evitar filtraciones por condensación.

[68 ]

Los pilonos también han sido objeto de actuaciones a los largo de estos años, sustituyéndose las cubiertas, reparando bajantes y rediseñando los sistemas de evacuación de aguas en su base.

Todas estas medidas, combinadas con mejoras en el mantenimiento del templo han servido para erradicar la amenaza del agua en su interior y debieran ser completadas en el futuro con la sustitución de las cubiertas en el mammisi y con la instalación de un climatizador que controle y corrija la humedad que se introduce por la puerta o aportan los propios visitantes.

Las medidas preventivas contra posibles acciones vandálicas han consistido en un aumento de la seguridad del recinto, sustituyendo a la policía municipal por agentes de seguridad que cubren la vigilancia del templo las 24 horas. Así mismo, se ha aumentado el personal de vigilancia en salas durante el horario de apertura al público. En total hay un mínimo de seis personas cubriendo distintos aspectos de la seguridad y vigilancia de Debod. Los protocolos de actuación de todo ese personal han sido modificados para prevenir y evitar daños al monumento y a las personas. Para potenciar aún más su seguridad y evitar la intrusión en el recinto fuera de los horarios de visita se ha planteado la necesidad de instalar una verja alrededor del perímetro del templo, sustituir las cancelas de acceso y dotar el conjunto de medidas de seguridad electrónica (detectores perimetrales y videovigilancia), especialmente en zonas como los pilonos o las fachadas oeste y sur, de más difícil control visual. Por otra parte, se ha asumido la competencia sobre las autorizaciones para rodajes y realización de actos en el templo y sus plataformas. En la actualidad se ha restringido al máximo la concesión de tales autorizaciones y en los pocos casos en que se otorga, se realizan bajo un estricto control facultativo.

La protección, en el interior del templo, de paramentos y objetos se ha confiado, además de a la vigilancia humana, al diseño expositivo, mediante la instalación de barreras (estructuras para soportes de información, catenarias), revestimientos de madera, cristales protectores $\mathrm{y}$ vitrinas que impiden un acceso directo a las zonas o elementos más importantes. 
Con el fin de reducir la masiva afluencia de visitantes al templo y limitar posibles daños, se han adoptado medidas de control y organización de la visita: establecimiento de número máximo de visitantes, limitación de la entrada cuando los valores máximos sean superados, reserva previa obligatoria y limitación de tiempos de visita para grupos y suspensión o reorganización de los programas de actividades de los fines de semana. Con la adopción de estas medidas se espera reducir el número de visitantes un $20 \%$ respecto a 2008. No obstante, si esas expectativas no se cumplieran cabe la posibilidad de extender la reserva previa a todos los visitantes, al menos durante las jornadas de fines de semana $\mathrm{y}$ festivos.

\section{Restauraciones}

Junto a la conservación preventiva, en los últimos años se han realizado distintas restauraciones en Debod. Éstas has afectado principalmente a varios sillares que sufrían graves afecciones por la presencia de vástagos y grapas metálicas en su interior, con alteraciones generalizadas e, incluso, fragmentación y pérdida de material. Además se ha iniciado un programa de limpieza de los sillares decorados expuestos en la terraza, que se ha de completar con la limpieza del naos de granito de Ptolomeo XII y la gola del segundo pilono.

La actuación restauradora más importante en ese periodo se realizó en los pilonos que presentaban importantes deterioros motivados por la humedad, así como por problemas estructurales, con grietas y roturas de sillares, así como riesgo de desprendimiento de la gola en el primero. Ambas estructuras fueron limpiadas, desaladas, se eliminaron todos los recrecidos y rejuntados que no cumplían una misión estructural, se eli- minaron las colonias biológicas, se rellenaron las grietas y fisuras, y los sillares fueron consolidados y sometidos a tratamiento de hidrofugación.

\section{EL PROYECTO DE INTERVENCIÓN DE 2005}

En diciembre de 2005, por encargo del Área de las Artes del Ayuntamiento de Madrid, la empresa Conservación del Patrimonio Artístico (CPA) realizó un trabajo de análisis del estado del templo, acompañado de una memoria de actuaciones recomendadas. Tanto el encargo como el documento entregado suponían un importante cambio cualitativo respecto a la conservación de Debod, planteándose por primera vez desde la concejalía una acción integral sobre el conjunto, en lugar de actuaciones parciales, cuando no puntuales, como las realizadas hasta ese momento.

Los trabajos realizados para la elaboración del proyecto han consistido en:

1.Recopilación y digitalización de la documentación planimétrica existente.

2.Recopilación y digitalización de la documentación gráfica del montaje en 1970-1972.

3.Recopilación y análisis de intervenciones restauradoras anteriores.

4.Escaneado del templo para la realización de un levantamiento planimétrico.

5.Escaneado de alta precisión de los relieves del vestíbulo, capilla de Adijalamani y relieves exteriores.

6.Identificación y codificación de los sillares del templo.

7.Identificación de morteros.

8.Análisis petrográfico de sillares y morteros.

Las actuaciones restauradoras incluidas en la memoria eran: limpieza de los paramentos; extracción de sales; tratamientos biocidas, trata- 
miento de fisuras y grietas; reintegración de volúmenes; rejuntado; consolidación; tratamiento de grapas; hidrofugación de los bloques de arenisca de Villamayor y tratamiento cromático de conjunto.

El proyecto planteaba además actuaciones sobre las cubiertas de los pilonos, mammisi y los patios interiores de la terraza, así como la instalación de un alero perimetral en la cubierta del templo que proyectara el agua a cierta distancia de la base de los muros. Así mismo, se recomendaban la restauración de las pendientes en el zócalo de granito del templo, con la finalidad, igualmente, de evitar humedades en los muros. El proyecto proponía también un programa de mantenimiento y la creación de una base de datos de sillares, lesiones e intervenciones, que documentara minuciosamente los procesos de deterioro.

En principio, un proyecto de estas características es una buena noticia para cuantos venimos trabajando en la conservación del templo y es, por supuesto, bienvenido. Muchos de los aspectos y tareas que plantea son de carácter urgente y ya habían sido demandados por el Museo en múltiples ocasiones anteriores. Especialmente necesaria era la realización de una fase de estudio y análisis científicos ya que, hasta la fecha, todos los informes de estado y diagnósticos de patologías realizados sobre el edificio estaban basados en indicadores visuales de alteraciones y [ 70 ] adolecían de la falta de una analítica científica y de series de datos mensurables con los que poder establecer conclusiones y desarrollar propuestas más ajustadas al estado real del monumento.

Sin embargo, el proyecto tiene también importantes carencias. La fase de estudios previos queda limitada a los informes petrológico y de morteros, que con ser importantes, son insuficientes y deberían ser completados con un estu- dio geotécnico del subsuelo en que se asienta el templo, localización de estructuras arqueológicas subyacentes (principalmente las del Cuartel de la Montaña), localización de elementos de servicio del parque (galerías, sistemas de riego, electricidad, etc.), análisis del funcionamiento estructural del edificio, localización de elementos metálicos en el interior de los sillares, caracterización de los principales materiales, análisis de sales, análisis microbiológicos y estudio de incidencia climática y ambiental, entre otros.

En materia de conservación preventiva, el proyecto sólo plantea mejoras en las cubiertas del templo y pilonos y en el zócalo de granito sobre el que se asientan. La construcción de un alero de plomo que se proyecta fuera de la línea de la gola es especialmente controvertido al modificar y distorsionar la lectura del monumento, sin que el beneficio buscado, eliminar la incidencia del agua de lluvia en los paramentos verticales exteriores, sea previsiblemente conseguido.

Pero sobre todo, el proyecto sigue ignorando las causas del deterioro del templo de Debod, limitándose, una vez más, a reparar los daños producidos a lo largo de estos años y, a lo sumo, a corregir algún elemento arquitectónico, para protegerlo parcialmente.

\section{Propuestas de actuación}

En varias ocasiones anteriores se han enunciado las posibles soluciones que cabría adoptar para la conservación del monumento y que básicamente se reducen a dos: mantener el templo en su estado actual intentando minimizar, que no eliminar, algunos de los factores de riesgo citados, o proceder a su cubrición.

En este último sentido, se han formulado ya diversas alternativas que contemplaban la protec- 
ción del edificio mediante la construcción de una cubierta realizada con materiales ligeros. Cubierta que puede ser parcial, sólo la parte superior, impidiendo la acción directa del agua sobre los sillares, o completa, encerrando el monumento en una especie de urna transparente. La posibilidad de alguna cobertura de este tipo para el templo de Debod fue planteada ya en 1970, especialmente tras la polémica suscitada en la prensa por la conservación del edificio ante las inclemencias de su primer invierno en Madrid. El propio alcalde Arias salía al paso de las críticas indicando que estaba previsto "si llega el caso, un revestimiento de cristal o una campana de plástico"4. Más recientemente Fort González (en 1997) o Madrid Muñoz, portavoz de UNESCO en Madrid, han propuesto soluciones similares ${ }^{5}$. Estas cubiertas, que son relativamente habituales en la protección de lugares arqueológicos, plantean, sin embargo, distintos tipos de problemas que es necesario ponderar: técnicos, ya que además de una cobertura efectiva que impida la entrada de agua, le son exigibles a la estructura así creada los más altos requerimientos de climatización y conservación preventiva, algo difícil de asegurar y muy costoso ${ }^{6}$; y estéticos, dada la necesidad de adecuar la construcción con el templo y su entorno y respetar la "línea de cielo" en esta zona de la ciudad.

En cualquier caso, tanto se mantenga el actual emplazamiento, sin protección, como si se adopta la solución de cubrir el conjunto, se deben tener en cuenta los usos y necesidades cada vez mayores que tiene el templo para el desarrollo de sus otras funciones museológicas. Cualquiera de estas dos opciones deberían ser completadas con la construcción de instalaciones anejas que permitan una adecuada atención al visitante (zonas de recepción, venta de entradas, tienda, aseos, zonas de exposición, interpretación o atención didáctica) y un correcto funcionamiento del museo (almacenes, instalaciones para el personal de servicio, instalaciones técnicas, de seguridad, conservación, de atención a investigadores, etc.).

Otra posible solución sería la construcción de una estructura arquitectónica de fábrica para albergar en su interior el templo. Las modernas técnicas de construcción e ingeniería pueden aportar soluciones innovadoras a los problemas que un edificio así plantea y que en su momento se consideraron poco menos que insuperables. Los requerimientos de conservación serían igualmente altos, pero más fáciles de mantener, al asegurarse un mayor aislamiento. Por otra parte, los inconvenientes estéticos que una obra en superficie podría comportar en una zona tan especial como la cornisa occidental de la ciudad, pueden solucionarse mediante su construcción total o parcialmente subterránea, con lo que el templo podría mantener el mismo emplazamiento, aunque unos metros por debajo del nivel actual. Al mismo tiempo, se solventarían las limitaciones para el desarrollo de las funciones museísticas en Debod, ya que no se trataría de una mera cobertura de un monumento, sino de un proyecto de museo, dotado de los espacios y medios necesarios para ejercer sus cometidos. A esta solución se han referido en dos ocasiones tanto la Concejalía de Cultura, como la propia Alcaldía de la ciudad e incluso

4. ABC, 26-12-1970: "Las piedras del templo de Debod resistirán cien o mil años en su actual emplazamiento".

5. Fort González 1997: 25; El Mundo, 11-03-2007: "La Unesco plantea cubrir el Templo de Debod con una campana de cristal".

6. Un ejemplo paradigmático lo constituye la historia de la protección del Ara Pacis en Roma. El pabellón original, construido en 1937 para proteger el altar, tuvo que ser remodelado, cambiando su acristalamiento, en 1950 y en 1970. A mediados de los años 90 era evidente que su capacidad de aislar de forma efectiva el monumento era insuficiente, revelándose numerosos problemas derivados de los cambios de temperatura, humedad y la contaminación atmosférica. Finalmente, en 1995 se decidió sustituir el viejo pabellón por un nuevo museo que lo alojara, obra de R. Meier. 
el Consejo Superior de Antigüedades egipcio demandó una salida similar?.

Esta es, de las posibles soluciones, la que asegura una conservación del templo más eficaz, al erradicar la mayor parte de los factores de riesgo y facilitar la efectividad de las medidas preventivas. Por otro lado, aseguraría el funcionamiento museístico del templo, posibilitando su expansión y desarrollo, y dotaría a la ciudad de una infraestructura cultural sobre una temática, Egipto y Nubia, de gran atractivo entre la población y escasamente representada en Madrid. Sin embargo, también es una opción que comporta importantes problemas técnicos, referidos a la estructura arquitectónica que se debería construir, a la manipulación del templo, así como la posible existencia en el subsuelo de otras estructuras con requerimientos de documentación arqueológica y quizás de conservación in situ (el Cuartel de la Montaña, al menos), que deberían ser objeto de estudios y análisis antes de tomar cualquier decisión al respecto.

Esta es la solución que venimos defendiendo desde el Museo Municipal, primero, y luego desde el Museo de los Orígenes. Pero esta opción no cuenta con el beneplácito de todos los sectores implicados en la conservación arquitectónica. La brecha existente entre las sensibilidades de conservadores de museos y egiptólogos, por un lado, y arquitectos de otro parece insalvable. Posiciones maximalistas como las expresadas [ 72 ] en una mesa redonda sobre el templo de Debod celebrada en el Colegio Oficial de Arquitectos de Madrid, donde se rechazó la instalación del templo de Dendur en el Metropolitan Museum de Nueva York y se afirmó preferir "la muerte" de Debod a su cubrición, hacen muy difícil la conciliación necesaria para lograr la mejor solución ${ }^{8}$.

A mi juicio, estas posturas arrancan de un enfoque erróneo sobre el templo en su instalación actual, entendiéndolo como un bien patrimonial inmueble, inalienable del lugar en que ha sido levantado y cuya conservación debe hacerse in situ y sin alterar su relación con el ambiente en que se encuentra. Sin embargo, el templo de Debod es un bien cultural muy especial. La decisión de removerlo de su establecimiento original en 1960, motivada por la necesidad de su preservación, ya produjo una modificación sustancial de su status de bien inmueble, transformándolo en un gigantesco objeto mueble. La condición establecida por el gobierno egipcio de que debía ser alojado en un edificio o en un museo refuerza esa valoración y nos debiera obligar a contemplarlo desde otra óptica.

Es cierto que el templo en su actual instalación es un monumento con el que nos hemos familiarizado los madrileños y muchos de los visitantes a la ciudad. Es cierto que el templo y los jardines en los que está enclavado constituyen uno de los parajes más exóticos y atractivos de Madrid, dando lugar a un conjunto urbanístico de gran interés. Es cierto que la fachada occidental de la ciudad, sobre el Manzanares, no debe ser visualmente alterada. Es cierto que las propuestas de cubrición o de inserción en un museo plantearían una lectura del templo radicalmente distinta a la actual, que provocaría cierta estupefacción y algún rechazo al enfrentarse a un edificio dentro de un edificio. Son ciertas esas y otras argumentaciones similares. Sin embargo, si adoptamos una posición rigurosa sobre la ilegitimidad de una remoción, también deberíamos convenir

7. ABC, 23-08-2002: "Estudian enterrar o cubrir el Templo de Debod para evitar su deterioro"; ABC, 16-03-2007: "El templo de Debod se conservaría mejor si no estuviera al aire libre, dice el Alcalde"; ABC, 15-05-2007: "Hawass exige que el templo de Debod esté en un museo".

8. Di Nobile 2005: 21. 
en que la reconstrucción del templo (de todos los templos nubios afectados por las actuaciones de los años 60-70) dio lugar a "un falso de sí mismo obtenido con sus propios materiales" (Brandi 1988: 78) que algunos parecen obstinarse en hacer más inalienable hoy en Madrid que en su estado y ubicación originales. Si en 1960, su conservación obligó a tomar la decisión "quirúrgica" y extrema, pero también legítima, de su desmontaje y traslado, incluso fuera del país en que fue construido, en la actualidad nuestra obligación de conservarlo en su integridad no tiene por qué asumir criterios más restrictivos. Si una vez fue movido por razones de conservación, las mismas razones justifican hoy su inclusión en un edificio que lo proteja de forma permanente y eficaz.

La reciente declaración del templo como Bien de Interés Cultural puede abrir una vía de acercamiento y conciliación de posturas. El texto califica el templo como inmueble y delimita un entorno de protección. Su ubicación en la Montaña del Príncipe Pío, dentro de los jardines actuales, se eleva a definitiva y deberá respetarse siempre la visión del conjunto monumental (templo y pilonos), sin elementos que perturben la comprensión integral del templo. Incluso la anastilosis de las fachadas queda protegida, prohibiéndose expresamente la retirada de los sillares de Villamayor. No obstante, la declaración no descarta la posibilidad de modificar las actuales condiciones del emplazamiento -lo que dejaría abierto el camino a su cubrición- siempre que las nuevas actuaciones se encaminen a garantizar su conservación, acrecentar su conocimiento, fomentar su difusión y que el bien no sufra menoscabo con ellas?.

En realidad, no es otra cosa la que se pretende con la propuesta aquí expresada de construir un museo que albergue el templo, que sería, a nuestro juicio, la mejor de las formas para asegurar tales condiciones. En cualquier caso, la solución que en un futuro pueda adoptarse para la protección del templo deberá ser objeto de un amplio debate entre egiptólogos, conservadores, arquitectos, así como las instituciones y organismos competentes en su protección. Un debate serio que entienda las especiales circunstancias por las que el templo está hoy en Madrid. Un debate profundo que contemple los aspectos más adecuados para su conservación, evitando condenar al templo a continuas restauraciones que al final no lleguen a impedir su ruina. Pero, también, un debate amplio en el que el desarrollo de las funciones museológicas de Debod y la necesidad de atender las demandas de servicios museísticos de sus visitantes tengan un peso destacado a la hora de seleccionar la opción definitiva.

9. DECRETO 39/2008, de 17 de abril, del Consejo de Gobierno de la Comunidad Autónoma de Madrid, por el que se declara Bien de Interés Cultural, en la categoría de monumento, el Templo de Debod. 


\section{Principales actuaciones de mantenimiento, conservación y restauración realizadas en Debod}

(1982-2008)

\begin{tabular}{l|l}
$\mathbf{1 9 8 2}$ & $\begin{array}{l}\text { Reparación de cubiertas del templo y pilonos y consolidación e impermeabilización de } \\
\text { paramentos }\end{array}$ \\
\hline $\mathbf{1 9 8 2}$ & $\begin{array}{l}\text { Consolidación e impermeabilización de paramentos verticales de pilonos y consolidación de } \\
\text { paramentos verticales del edificio principal }\end{array}$ \\
\hline $\mathbf{1 9 8 2}$ & Reparaciones en el zócalo: levantado de losas, impermeabilización y nuevo solado \\
\hline $\mathbf{1 9 8 2}$ & Obras de saneamiento y canalización de desagües hasta acometida general \\
\hline $\mathbf{1 9 9 2}$ & Obras de reparación de la cubierta del templo \\
\hline $\mathbf{1 9 9 7}$ & Restauración de dos sillares del muro oeste del templo de Debod \\
\hline $\mathbf{1 9 9 8}$ & Sustitución de la iluminación monumental del templo \\
\hline $\mathbf{1 9 9 8}$ & $\begin{array}{l}\text { Reparación de la lámina delgada: levantamiento de adoquinado, reparación de pozos de } \\
\text { evacuación e impermeabilización de la base }\end{array}$ \\
\hline $\mathbf{1 9 9 8}$ & Restauración de los dos pilonos del templo de Debod \\
\hline $\mathbf{1 9 9 9}$ & $\begin{array}{l}\text { Instalación de una mampara de vidrio (doble acristalamiento con cámara de aire y estructura } \\
\text { metálica sellada con silicona) y puerta de acceso de apertura automática en el vestíbulo }\end{array}$ \\
\hline $\mathbf{2 0 0 2}$ & Instalación de nueva cubierta de plomo, con capa de aislante intermedia \\
\hline $\mathbf{2 0 0 2}$ & Sustitución de maquinaria de aire acondicionado y reparación de conducciones \\
\hline $\mathbf{2 0 0 2}$ & Limpieza de dos sillares con decoración 1972/001/13 y 1972/001/15 \\
\hline $\mathbf{2 0 0 6}$ & $\begin{array}{l}\text { Restauración de las cubiertas de los pilonos y obras de restauración de pendientes en el zócalo del } \\
\text { templo }\end{array}$ \\
\hline $\mathbf{2 0 0 7}$ & Limpieza de pintadas en fachada posterior del templo \\
\hline $\mathbf{2 0 0 7}$ & Restauración arquitectónica de las cubiertas de los patios lucernarios
\end{tabular}




\section{Bibliografía}

BRANDi, C.

1988 Teoría de la restauración. Madrid.

Cervelló Autori, J.; Díaz de Cerio, M. y Rull Ribó, D.

2005 Presentación, en Cervelló Autori, J.; Díaz de Cerio, M. y Rull Ribó, D.: Actas del Segundo Congreso Ibérico de Egiptologia. Belaterra, 12-15 de marzo de 2001, (Aula Aegyptiaca-Stvdia 5), Bellaterra: 7-14.

Di NóBiLe, L.

2005 Coloquio en Madrid sobre Debod: Propuestas sobre la mesa, Boletín de Amigos de la Egiptología XXV: 20-21.
ForT GONZÁLEZ, R.

1997 El templo de Debod. Soluciones a su deterioro, Restauración y Rehabilitación 10: 18-23.

JaRAmago CANORA, M.

1988 El templo de Debod: factores de degradación. Revista de Arqueología 88: 34-43.

Martín Flores, A.

1994 Templo de Debod. Estado de Conservación y propuestas de actuación, Estudios de Prehistoria y Arqueología Madrileña 9: 117128.

2001 La función museística de Debod. Su difusión y exposición pública, en Debod, tres décadas de historia en Madrid. Madrid, 121-141. 


\section{Trabajos de Egiptología Papers on Ancient Egypt}

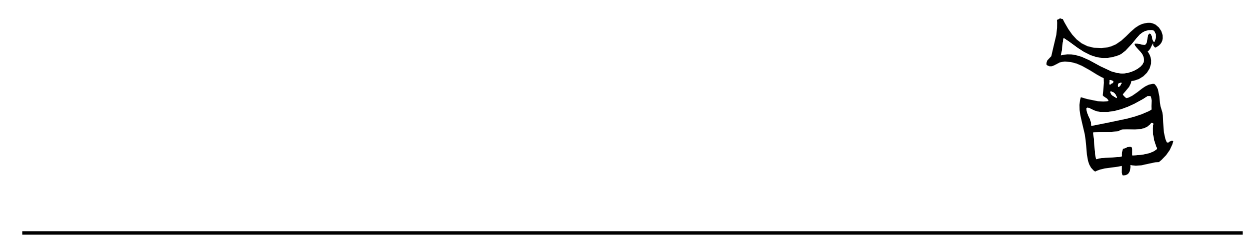

Número 5/2 2009 


\section{Actas \\ III Congreso Ibérico de Egiptología III Congresso Ibérico de Egiptologia}

Editores

Miguel Ángel Molinero Polo Covadonga Sevilla Cueva 


\title{
Editor
}

Miguel Ángel Molinero Polo

Universidad de La Laguna

\section{Consejo Editorial}

\author{
Antonio Pérez Largacha \\ Universidad de Castilla-La Mancha \\ José-R. Pérez-Accino \\ Birkbeck, Universidad de Londres \\ Covadonga Sevilla Cueva \\ Universidad Autónoma de Madrid
}

\section{Comité Científico}

Josep Cervelló i Autuori

Universitat Autònoma de Barcelona

$\mathrm{M}^{\mathrm{a}}$ José lópez Grande

Universidad Autónoma de Madrid

Josep Padró i Parcerisa

Universitat de Barcelona

$\mathrm{M}^{\mathrm{a}}$ Carmen Pérez Die

Museo Arqueológico Nacional, Madrid

Ester Pons Mellado

Museo Arqueológico Nacional, Madrid

José M. Serrano Delgado

Universidad de Sevilla

\section{Colaboradores Editoriales}

Linda Steynor

English editorial assistant

Hervé Mouriacoux

Assistant éditorial pour la langue française 
Trabajos de Egiptología está producida por Isfet. Egiptología e Historia c/ Blanco $1,2^{\circ}$

38400 Puerto de la Cruz

Tenerife-Islas Canarias

España

Maquetación: Proyecto Limón

(C) Autores de los artículos aparecidos

y Consejo Editorial de Trabajos de Egiptología - Papers on ancient Egypt

Depósito Legal: TF-2303-2009

ISSN: $1695-4750$

Imprime: Gráfica Los Majuelos, S.L.L.

imprenta@graficaslosmajuelos.com

Tfno.: 922311455 


\section{Comité Científico \\ III Congreso Ibérico de Egiptología III Congresso Ibérico de Egiptologia}

Miguel Á. Molinero Polo

Universidad de La Laguna

Presidente del Comité Organizador del III Congreso Ibérico de Egiptología

Miembro del Comité Organizador del I Encuentro de Egiptología

Josep Cervelló Autuori

Universitat Autònoma de Barcelona

Presidente del Comité Organizador del II Congreso Ibérico de Egiptologia

José Manuel Galán Allué

Consejo Superior de Investigaciones Cientificas

Director del Proyecto Djehuty, Luxor, Egipto

$\mathrm{M}^{\mathrm{a}}$ Helena Trindade Lopes

Universidad de Lisboa

Directora de la Misión Arqueológica Portuguesa en Menfis

Josep Padró i Parcerisa

Universitat de Barcelona

Director de la Misión Arqueológica de Oxirrinco

Antonio Pérez Largacha

Universidad de Castilla - La Mancha

Miembro del Comité Organizador del I Encuentro de Egiptología

José Ramón Pérez-Accino

Birkbeck College, University of London

Miembro del Comité Organizador del I Encuentro de Egiptología

$\mathrm{M}^{\mathrm{a}}$. Carmen Pérez Díe

Museo Arqueológico Nacional

Directora de la Misión Arqueológica Española en Heracleópolis Magna, Egipto

Covadonga Sevilla Cueva

Universidad Autónoma de Madrid

Miembro del Comité Organizador del I Encuentro de Egiptología 